\title{
Correlation of Paraspinal Atrophy and Denervation in Back Pain and Spinal Stenosis Relative to Asymptomatic Controls
}

\author{
John A. Yarjanian, DO, April Fetzer, DO, Karen S. Yamakawa, MS, \\ Henry C. Tong, MD, Matthew Smuck, MD, Andrew Haig, MD
}

Objective: To determine the relationship among spinal stenosis, back pain, paraspinal muscle denervation, and paraspinal muscle atrophy.

Design: A prospective masked, double-controlled study.

Setting: A university hospital and outpatient spine clinic.

Participants: Ten asymptomatic subjects, 10 subjects with mechanical low back pain, and 15 subjects with symptomatic spinal stenosis; age range, 55-80 years old.

Interventions: Magnetic resonance imaging measurements of minimum spinal canal diameter, paraspinal muscle cross-sectional area at the level of the L5-S1 disk, and quantified paraspinal electrodiagnostic testing (MiniPM) were performed by examiners blinded to each other's results and to the participants' clinical information.

Main Outcome Measurements: Paraspinal muscle cross-sectional area and MiniPM scores.

Results: A paraspinal cross-sectional area decreased significantly from asymptomatic subjects $\left(3872 \mathrm{~mm}^{2}\right)$ to subjects with low back pain $\left(3627 \mathrm{~mm}^{2}\right)$ and to subjects with spinal stenosis $\left(2985 \mathrm{~mm}^{2}\right)$. In the stenosis group, there was a trend toward increased paraspinal denervation in the subjects with severe spinal stenosis, but this was not statistically significant.

Conclusions: Symptomatic spinal stenosis results in greater paraspinal muscle atrophy than low back pain alone. The extent of paraspinal atrophy was not significantly explained by the extent of denervation, thus, it may be reversible, and the role of paraspinal muscle rehabilitation in patients with spinal stenosis deserves further study.

PM R 2013;5:39-44

\section{INTRODUCTION}

Lumbar spinal stenosis is a common and potentially disabling condition most often encountered in older adults. A classic symptom of spinal stenosis, termed pseudoclaudication, is lower limb pain with ambulation that is improved with rest or with a flexed spine position [1]. The exact mechanism behind the symptoms of spinal stenosis is unknown but may relate to compromise in the vasa nervorum of the spinal roots aggravated by the increasing metabolic demand of ambulation [2].

Although magnetic resonance imaging (MRI) is commonly used to establish the extent of spinal canal stenosis, the severity of stenosis frequently does not relate to patient symptom severity $[3,4]$. Electromyography $(E M G)$ is often used to assist in the diagnosis of spinal stenosis and the elimination of other differential diagnoses [5]. It is well documented that paraspinal denervation occurs in subjects with spinal stenosis [5-7]. In one study, isolated paraspinal denervation without extremity evidence for radiculopathy was found in subjects with degenerative spine changes and radiating symptoms, whereas those with nonradiating back pain had normal findings [8]. Stretching of the posterior primary ramus, rather than injury to the nerve root itself, is a potential mechanism for this denervation [8]. Although nonradiating back pain is not accompanied by paraspinal denervation, a study has shown that some level of background denervation occurs in asymptomatic subjects, perhaps increasing with age [9].

\begin{abstract}
J.A.Y. Physical Medicine and Rehabilitation, University of Michigan Health System, $325 \mathrm{E}$ Eisenhower, Suite 200, Ann Arbor, MI 48108. Address correspondence to: J.A.Y.; e-mail: johny@med.umich.edu

Disclosure: grant, direct funds received and money paid to institution, $\mathrm{NIH}$ grant \#ROI WD059259
\end{abstract}

A.F. Midwest Orthopedics, Rush University, Chicago, IL

Disclosure: nothing to disclose

K.S.Y. Physical Medicine and Rehabilitation University of Michigan Health System, Ann Arbor, Ml

Disclosure: grants, University of Michigan

H.C.T. Michigan Head and Spine Institute, Southfield, MI

Disclosure: nothing to disclose

M.S. Physical Medicine and Rehabilitation Stanford University, Stanford, CA

Disclosure: board membership, The Spine Journal; consultancy, Arthrocare Corp.; grants/grants pending (money to institution), Cytonics Corp.; payment for lectures, North American Spine Society, Instructional Course Honoraria; travel/meeting expenses, North American Spine Society

A.H. Physical Medicine and Rehabilitation, University of Michigan Health System, Ann Arbor, MI

Disclosure: Haig et al Consulting; speaker, multiple academic centers; expert witness, occasional legal cases; grant, NIH \#R01H00592559, Center for Healthcare Research and Transformation; nonfinancial, president of the International Rehab forum and Board of International Societies of PM\&R

Peer reviewers and all others who control content have no relevant financial relationships to disclose.

The project described was supported by Award \#R01HD059259 from the Eunice Kennedy Shriver National Institution of Child Health and Human Development. The content is solely the responsibility of the authors and does not necessarily represent the official views of the Eunice Kennedy Shriver National Institution of Child Health and Human Development or the $\mathrm{NIH}$.

Submitted for publication March 14, 2012; accepted August 24, 2012 
Quantitative EMG testing is used to evaluate the extent of paraspinal muscle denervation in persons with spinal stenosis and lumbar spine problems. Haig et al $[9,10]$, Haig [11], and Tong et al [12] developed a clinical protocol named MiniPM that has anatomical validity, clinical relevance, a range of normals, and good interrater reliability. This technique can be used to quantify paraspinal denervation with good specificity [13].

A decreased lumbar paraspinal muscle cross-sectional area may also relate to spinal symptoms, including axial low back pain and neurogenic claudication. Computed tomography measurements of the paraspinal muscle cross-sectional area in patients with low back pain have been shown to be reliable [14]. MRI has also been used to determine the functional cross-sectional area of lumbar paraspinal muscles [15]. However, the relationship between the lumbar paraspinal muscle cross-sectional area and spinal symptoms has not been previously examined, except in a case report of disk herniation [16]. Also, the relationship between the lumbar paraspinal muscle cross-sectional area, paraspinal muscle denervation, and spinal stenosis has not been previously examined.

The primary purpose of the current study was to determine whether the lumbar paraspinal muscle cross-sectional area and paraspinal denervation are different in subjects without symptoms, with low back pain, and with clinical lumbar stenosis. The second purpose of this study was to determine if the paraspinal muscle cross-sectional area, paraspinal muscle denervation, and minimal lumbar spinal canal diameter were correlated with each other in subjects with clinical lumbar spinal stenosis.

\section{PATIENTS AND METHODS}

This study was done with 35 subjects recruited for a much larger study. At a university hospital, 150 participants between ages 55-80 years were recruited. The first 90 participants were obtained from the university MRI studies where the neuroradiologist's preliminary reading indicated existence of lumbar spinal stenosis. Another 30 had nonradiating low back pain without MRI evidence of spinal stenosis. The final 30 participants were asymptomatic volunteers recruited from the community who subsequently completed a lumbosacral MRI under the study protocol. Volunteers were excluded from the study if they met any of the following criteria: polyneuropathy, diabetes, heavy alcohol use, previous spine surgery, and/or relative contraindications to MRI or EMG. All qualifying subjects were given informed consent and were compensated for participation. The study was HIPPA (Health Insurance Portability and Accountability Act of 1996) compliant and approved by the university's institutional review board.

The 150 participants were separated into 3 groups (asymptomatic, back pain, clinical spinal stenosis) based on a physician's clinical evaluation. A physiatrist (A.H.) reviewed the participant's clinical questionnaire that contained answers to questions about back pain, leg pain, neurologic symptoms, and functional limitations. Afterward, the physiatrist completed a comprehensive spinal history and physical examination. The physiatrist had no information from the participant's radiographic and electrodiagnostic tests. The physiatrist and the neurosurgeon rendered an opinion as to whether the subject was asymptomatic; had low back pain without spinal stenosis; or had mild, moderate, or severe spinal stenosis. A neuroradiologist blinded to the subjects' clinical status reviewed each MRI; rendered an opinion regarding the presence of mild, moderate, or severe spinal stenosis; and measured the central canal anteroposterior (AP) diameter in $\mathrm{mm}$ at each level from L1-2 to L5-S1. Next, an electrodiagnostician (A.H., J.Y., H.T., or A.F.) also blinded to the subjects clinical status performed quantitative paraspinal muscle EMG testing by using the MiniPM technique bilaterally [9] The MiniPM technique, described elsewhere in detail [17], is a modification of the original Paraspinal Mapping technique that focuses primarily on the lumbar multifidus, which is the primary muscle at the lumbosacral junction.

From this study population, 35 participants with completed data were selected by a research assistant to include 10 asymptomatic subjects, 15 subjects with clinical spinal stenosis by both the radiologist's interpretation of the MRI and the physiatrist's interpretation of the history and physical examination, and 10 subjects with nonradiating low back pain and without stenosis on MRI. For all 35 subjects, measurement of the bilateral lumbar paraspinal muscle functional cross-sectional area (the area of muscle isolated from fat) was performed at the level of the L5-S1 disk on a T2-weighted axial image. This location was chosen to include the cross-sectional area of the multifidus from L5, L4, and L3 as they traverse to the sacrum [18]. By using standard region of interest (ROI) software, 2 physiatrists (J.Y. or A.F.) not involved in the previous analysis of these participants, independently traced the borders of the muscles to determine the muscle cross-sectional area in $\mathrm{cm}^{2}$, for both the right and left sides. The paraspinal cross-sectional areas for both the left and right side were added together for each subject. The results of both physiatrists for each subject were then averaged together to obtain the final paraspinal muscle crosssectional area for each subject. Elliott et al [19] by using axial Tl-weighted images found significant $(P<.001)$ side-byside differences in MRI measurement of regional cross sectional area (rCSA) of the semispinalis cervicis/capitis, multifidus, splenius capitis, and upper trapezius.

\section{Statistical Analyses}

Data were initially entered into a Microsoft Excel (Redmond, WA) database in which errors were checked and cleaned. SPSS version 11.5 (SPSS Inc, Chicago, IL) was used for 
Table 1. Population demographics for the 3 subject groups

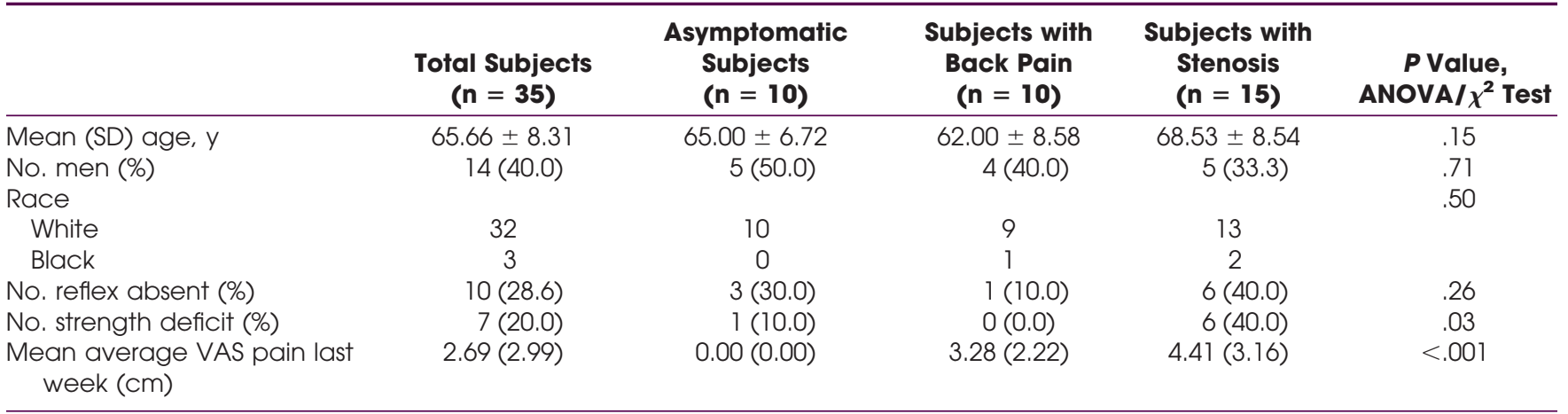

ANOVA = analysis of variance; $\mathrm{SD}=$ standard deviation; VAS = visual analog scale.

statistical analysis. All analyses were completed with comparisons among the 3 clinical subgroups. Analysis of variance was used to test the hypothesis that group means are equal, and the Tukey honestly significant difference test was performed to determine which means differ. The $\chi^{2}$ test was used to evaluate for statistical differences in the demographic features of each group. Also, the Pearson correlation analysis was used to examine the relationship between MRI measures and MiniPM scores.

\section{RESULTS}

The description of the patient population can be found in Table 1 . There were $40 \%$ men, a mean age of 65.6 years, and 32 were white. No statistically significant differences were observed across groups with respect to age, gender, race, or decreased reflexes. The presence of any strength deficit in the legs was higher in the spinal stenosis group $(P=.03)$. The groups differed significantly in visual analog pain scores (from 0-10), which averaged 0 in the asymptomatic group, compared with 3.28 in the low back pain group, versus 4.41 in the stenosis group. $(P \leq .001)$.

When comparing central canal AP diameters at each level, the smallest values were found at the L5-S1 level in each group. As shown in Table 2, the smallest central canal AP diameter $(9.47 \mathrm{~mm})$ in the asymptomatic group was smaller than the smallest central canal AP diameter $(15.76 \mathrm{~mm})$ in the stenosis group $(P<.001)$, and the average of the smallest 2 central canal AP diameters $(11.13 \mathrm{~mm})$ in the asymptomatic group was smaller than the average of the smallest 2 central canal AP diameters $(16.66 \mathrm{~mm})$ in the stenosis group $(P<.001)$. Similarly, the smallest central canal AP diameter ( $9.47 \mathrm{~mm}$ ) in the asymptomatic group was smaller than the smallest central canal AP diameter $(14.57 \mathrm{~mm})$ in the low back pain group $(P<.001)$, and the average of the smallest 2 central canal AP diameters $(11.13 \mathrm{~mm})$ in the asymptomatic group was smaller than the average of the smallest 2 central canal AP diameters $(15.46 \mathrm{~mm})$ in the low back pain group $(P<.001)$. Also shown in Table 2 , the paraspinal cross-

Table 2. Relationships between asymptomatic, back pain, and stenosis for anterior posterior canal stenosis, paraspinal crosssectional area, and paraspinal mapping score

\begin{tabular}{|c|c|c|c|c|c|c|c|c|}
\hline & $\begin{array}{l}\text { All Subjects } \\
\text { Mean (SD) }\end{array}$ & $\begin{array}{l}\text { Asymptomatic } \\
\text { Subjects, } \\
\text { Mean (SD) }\end{array}$ & $\begin{array}{l}\text { Back Pain, } \\
\text { Mean (SD) }\end{array}$ & $\begin{array}{l}\text { Stenosis, } \\
\text { Mean (SD) }\end{array}$ & $\begin{array}{l}\text { ANOVA } \\
\text { P Value }\end{array}$ & $\begin{array}{c}\text { Asymptomatic } \\
\text { vs. Back Pain } \\
\text { P Value }\end{array}$ & $\begin{array}{l}\text { Asymptomatic } \\
\text { vs. Stenosis } \\
\text { P Value }\end{array}$ & $\begin{array}{c}\text { Back Pain } \\
\text { vs. } \\
\text { Stenosis } \\
\text { P Value }\end{array}$ \\
\hline AP canal L1-2, mm & $20.41 \pm 3.45$ & $21.03 \pm 2.67$ & $21.18 \pm 1.80$ & $19.48 \pm 4.53$ & .39 & .99 & .52 & .46 \\
\hline AP canal L2-3, mm & $19.54 \pm 3.14$ & $21.20 \pm 3.19$ & $19.48 \pm 2.19$ & $18.48 \pm 3.34$ & .10 & .42 & .08 & .70 \\
\hline AP canal L3-4, $\mathrm{mm}$ & $18.15 \pm 3.39$ & $19.63 \pm 1.95$ & $18.87 \pm 3.66$ & $16.69 \pm 3.55$ & .07 & .86 & .08 & .23 \\
\hline AP canal L4-5, mm & $14.60 \pm 3.68$ & $17.61 \pm 1.51$ & $16.28 \pm 2.29$ & $11.47 \pm 3.00$ & $<.001$ & .46 & $<.001$ & $<.001$ \\
\hline AP canal L5-S1, mm & $13.81 \pm 3.41$ & $16.00 \pm 3.08$ & $15.06 \pm 1.83$ & $11.51 \pm 3.14$ & .001 & .74 & .001 & .01 \\
\hline $\begin{array}{l}\text { Average of smallest } \\
2 \text { AP canals, } \mathrm{mm}\end{array}$ & $13.94 \pm 3.17$ & $16.66 \pm 2.20$ & $15.46 \pm 1.64$ & $11.13 \pm 2.06$ & $<.001$ & .38 & $<.001$ & $<.001$ \\
\hline $\begin{array}{l}\text { Smallest AP canal } \\
\text { level, mm }\end{array}$ & $12.73 \pm 3.53$ & $15.76 \pm 2.72$ & $14.57 \pm 1.57$ & $9.47 \pm 1.91$ & $<.001$ & .42 & $<.001$ & $<.001$ \\
\hline $\begin{array}{l}\text { Paraspinal cross- } \\
\text { sectional area, } \\
\text { total right plus left, } \\
\mathrm{mm}^{2}\end{array}$ & $3422.60 \pm 930.12$ & $3872.80 \pm 892.84$ & $3627.60 \pm 990.38$ & $2985.80 \pm 760.78$ & .04 & .80 & .04 & .18 \\
\hline $\begin{array}{l}\text { Paraspinal mapping } \\
\text { score }\end{array}$ & $3.71 \pm 4.80$ & $3.40 \pm 6.10$ & $3.90 \pm 4.23$ & $3.80 \pm 4.52$ & .97 & .97 & .98 & .999 \\
\hline
\end{tabular}

$\mathrm{SD}=$ standard deviation; $\mathrm{ANOVA}=$ analysis of variance; $\mathrm{AP}=$ anteroposterior. 
Table 3. Correlations among paraspinal cross-sectional area, smallest canal diameter, and MiniPM score in subjects with clinical spinal stenosis

\begin{tabular}{lccc}
\hline & $\begin{array}{c}\text { Paraspinal Muscle } \\
\text { Cross-sectional } \\
\text { Area mm², Total } \\
\text { Area } 8 \text { Plus Left, } \\
\text { Correlation } \\
\text { Coefficient } \\
\text { (P value) }\end{array}$ & $\begin{array}{c}\text { Smallest } \\
\text { Canal AP } \\
\text { Diameter, } \\
\text { Correlation } \\
\text { Coefficient } \\
\text { (P value) }\end{array}$ & $\begin{array}{c}\text { Mini PM } \\
\text { Score } \\
\text { Correlation } \\
\text { Coefficient } \\
\text { (P value) }\end{array}$ \\
\hline $\begin{array}{l}\text { MiniPM score } \\
\text { Smallest canal }\end{array}$ & $.19(.50)$ & $.08(.78)$ & 1 \\
AP diameter & $.08(.76)$ & 1 & \\
(mm) & & & \\
\hline
\end{tabular}

$\mathrm{AP}=$ anteroposterior.

sectional area in the spinal stenosis group, of $2985 \mathrm{~mm}^{2}$, was decreased compared with the asymptomatic group, of 3872 $\mathrm{mm}^{2}(P=.04)$, but was not significantly decreased compared with the low back pain group, of $3627 \mathrm{~mm}^{2}(P=.18)$. The paraspinal MiniPM score of 3.8 in the spinal stenosis group and 3.9 in the low back pain group were higher than the asymptomatic group mean score of 3.4, but this was not statistically significant $(P=.97)$. The radiologist findings and impression of the severity of stenosis at the L5-S1 level in the stenosis group indicted that 3 of $15(20 \%)$ did not have stenosis at this level but disk bulge $(n=1)$, degenerative disk disease and facet joint disease ( $\mathrm{n}=1)$, and moderate central canal stenosis at L4-L5 $(n=1)$. One subject (7\% [1/15]) had severe spinal canal stenosis and neural foraminal narrowing, and facet hypertrophy and ligamentum flavum hypertrophy, whereas the remaining 11 (73\%) were found to have mildto-moderate stenosis due to disk bulge, disk protrusion, facet degenerative changes, facet hypertrophy, and ligamentum flavum hypertrophy.

When the paraspinal muscle cross-sectional area, MiniPM score, and the smallest canal AP diameter were correlated with each other, as shown in Table 3, none of the correlations were very high. However, as shown in Table 4, when the stenosis subjects were broken down into groups of increased severity, the paraspinal muscle cross-sectional area decreased and the MiniPM score increased. This finding was not significant, probably due to small sample sizes in each stenosis severity group.

\section{DISCUSSION}

The current study set out to determine the relationships among paraspinal muscle atrophy, paraspinal denervation, and clinical spinal stenosis. In general, we demonstrated that the paraspinal muscle cross-sectional area decreased from asymptomatic to back pain and from back pain to stenosis. This study also suggested logical relationships when clinical spinal stenosis increased, the paraspinal muscle cross-sectional area decreased, and the paraspinal denervation increased, which was likely not statistically significant due to the small size of the spinal stenosis subgroups.

Physical examination findings and demographics suggest that the 3 populations were reasonably comparable cohorts. Strength deficits and reflex changes were few but trended toward supporting the diagnosis of spinal stenosis in the asymptomatic group. Pain was worse in the stenosis group than in the back pain group.

The study methodology has certain strengths and limitations. The blinded examiners and the presence of 2 different control groups help to ensure that the findings are valid. A larger number of subjects, especially those within each of the spinal stenosis subgroups, may have revealed trends between denervation and atrophy. Measurement of paraspinal density did not include estimates of fatty replacement of muscles because accurate measurement of muscle density is difficult to perform accurately. A concerted effort was made during tracing of the paraspinal cross-sectional area to "trace out" fatty replacement whenever possible, as noted in Figures 1 and 2.

Past studies indicated that diagnostic tests such as myelogram, CT, and MRI do not correlate well with the extent of stenosis symptoms or with treatment efficacy $[20,21]$. In this study, by measuring the paraspinal cross-sectional area, we determined that there was a higher level of paraspinal atrophy in symptomatic subjects with MRI-documented spinal stenosis. Analysis of our data indicates that there is a statistically significant relationship between the paraspinal crosssectional area at the L5-S1 level in asymptomatic subjects and subjects with stenosis. Thus, the paraspinal cross-sectional area may be an important factor to consider when differentiating between mechanical back pain and spinal stenosis as well as in determining the severity and progression of stenosis symptoms.

Table 4. Paraspinal cross sectional area and MiniPM scores arranged by stenosis severity

\begin{tabular}{|c|c|c|c|c|}
\hline & $\begin{array}{l}\text { Mild Stenosis, } \\
\text { Mean (SD) }\end{array}$ & $\begin{array}{c}\text { Moderate Stenosis, } \\
\text { Mean (SD) }\end{array}$ & $\begin{array}{l}\text { Severe Stenosis, } \\
\text { Mean (SD) }\end{array}$ & $\begin{array}{l}\text { ANOVA, } \\
\text { P Value }\end{array}$ \\
\hline No. subjects & 3 & 7 & 5 & \\
\hline Paraspinal mapping score & $1.67 \pm 0.58$ & $2.29 \pm 4.35$ & $7.20 \pm 4.60$ & .11 \\
\hline
\end{tabular}

$\mathrm{SD}=$ standard deviation; ANOVA = analysis of variance. 


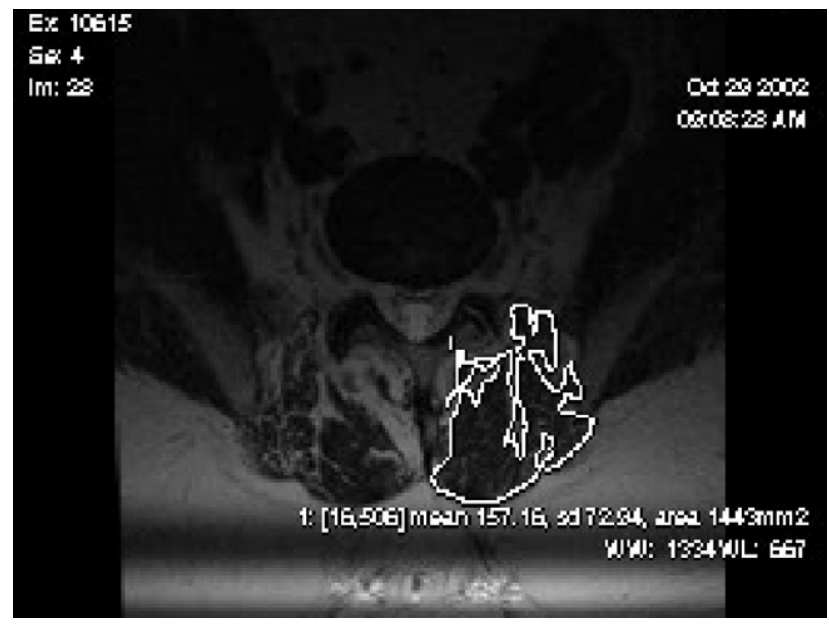

Figure 1. Lumbar paraspinal mapping technique.

With respect to AP diameter, statistically significant findings between the low back pain and spinal stenosis groups were noted only at the L4-5 and L5-S1 levels, which makes sense, because lumbar spine findings usually occur at the lower lumbar levels. However, atrophy was not related to denervation in this study, so it is unclear as to whether higher-level lesions will show differential atrophy in the paraspinals muscles. It is important to note that the radiographic severity of spinal stenosis in this study does not consistently correlate with the degree of spinal stenosis severity on clinical impression. The smallest AP canal diameter was easily differentiated between subjects with spinal stenosis and normal subjects, however, did not differentiate between the subjects with spinal stenosis and the subjects with low back pain. Furthermore, electrodiagnostic findings in subjects with clinically significant spinal stenosis may in-

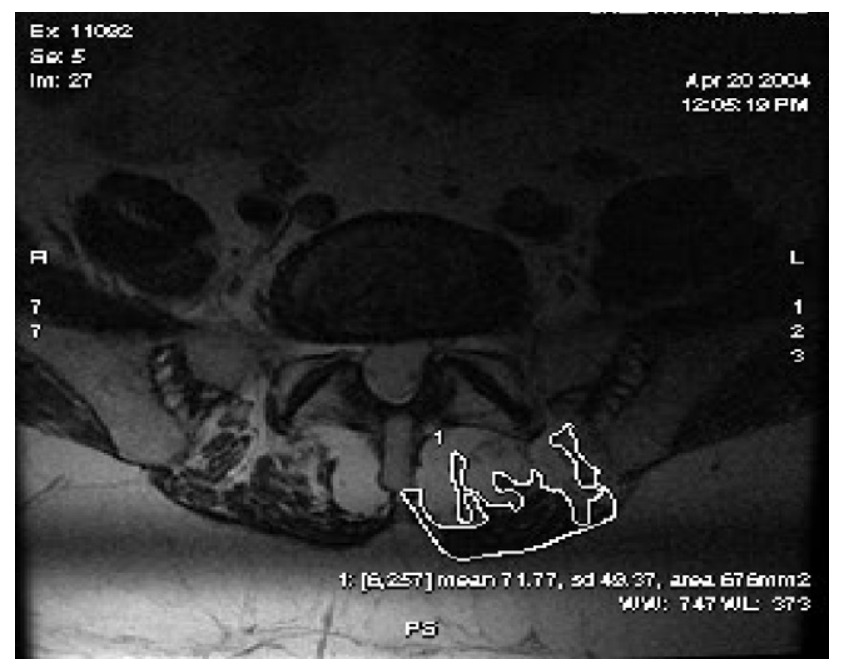

Figure 2. Lumbar paraspinal mapping technique. crease with clinical spinal stenosis severity. The small subgroup sample sizes prevented this study from finding significance.

The findings that patients with spinal stenosis have paraspinal atrophy without denervation suggest valid clinical implications. If atrophy of spinal stenosis is related to denervation, then one may presume that denervation was caused from entrapment or inflammation of the nerve roots or posterior primary rami. Conversely, non-neurogenic atrophy suggests disuse related to the mechanism of the disease; vascular claudication of the vasa nervorum in the spine may result in temporary nerve dysfunction without any anatomic disruption of the neurons. This may cause the patient to stop exercising long before the muscle fibers have a chance to fatigue, thus preventing muscle conditioning and sustained muscle mass. This concept is supported by a study that compared muscle fatigue to denervation in spinal stenosis, in which it was concluded that fatigue was not related to denervation [22]. Under this premise, we believe that paraspinal muscle atrophy related to spinal stenosis may be reversible. It may be possible to strengthen the paraspinal muscles in a flexed trunk position with greater tolerance due to a lack of vasa nervorum compression. Such training may improve postural tolerance and function in this patient population. Further study is necessary to investigate this hypothesis.

\section{CONCLUSION}

Symptomatic spinal stenosis results in greater paraspinal muscle atrophy than low back pain alone. The extent of paraspinal muscle atrophy was not significantly explained by the extent of denervation. Thus, it may be reversible, and the role of paraspinal muscle rehabilitation in patients with spinal stenosis deserves further study. Clinicians may find value in evaluating the paraspinal muscles on MRI in patients with low back pain and spinal stenosis.

\section{REFERENCES}

1. Deen HG Jr, Zimmerman RS, Lyons MK, McPhee MC, Verheijde JL, Lemens SM. Measurement of exercise tolerance on the treadmill in patients with symptomatic lumbar spinal stenosis: A useful indicator of functional status and surgical outcome. J Neurosurg 1995;83:27-30.

2. Porter RW. Spinal stenosis and neurogenic claudication. Spine (Phila $\mathrm{Pa}$ 1976) 1996;21:2046-2052.

3. Deyo RA. Magnetic resonance imaging of the lumbar spine. Terrific test or tar baby? N Engl J Med 1994;331:115-116.

4. Enzmann DR. On low back pain. AJNR Am J Neuroradiol 1994;15:109113

5. Wilbourn AJ, Aminoff MJ. AAEM minimonograph 32: the electrodiagnostic examination in patients with radiculopathies. American Association of Electrodiagnostic Medicine. Muscle Nerve 1998;21:16121631.

6. Jacobson RE. Lumbar stenosis. An electromyographic evaluation. Clin Orthop Relat Res 1976:68-71. 
7. Seppalainen AM, Alaranta H, Soini J. Electromyography in the diagnosis of lumbar spinal stenosis. Electromyogr Clin Neurophysiol 1981;21: 55-66.

8. Sihvonen T, Lindgren KA, Airaksinen O, Manninen H. Movement disturbances of the lumbar spine and abnormal back muscle electromyographic findings in recurrent low back pain. Spine (Phila Pa 1976) 1997;22:289-295.

9. Haig AJ, LeBreck DB, Powley SG. Paraspinal mapping. Quantified needle electromyography of the paraspinal muscles in persons without low back pain. Spine (Phila Pa 1976) 1995;20:715-721

10. Haig AJ, Moffroid M, Henry S, Haugh L, Pope M. A technique for needle localization in paraspinal muscles with cadaveric confirmation. Muscle Nerve 1991;14:521-526.

11. Haig AJ. Clinical experience with paraspinal mapping. I: Neurophysiology of the paraspinal muscles in various spinal disorders. Arch Phys Med Rehabil 1997;78:1177-1184.

12. Tong HC, Young IA, Koch J, Haig AJ, Yamakawa KS, Wallbom A. Paraspinal electromyography that compares concentric with monopolar needles: A blinded study. Am J Phys Med Rehabil 2003;82: 917-924.

13. Tong HC, Haig AJ, Yamakawa KS, Miner JA. Paraspinal electromyography: Age-correlated normative values in asymptomatic subjects. Spine (Phila Pa 1976) 2005;30:E499-E502.

14. Keller A, Gunderson R, Reikeras O, Brox JI. Reliability of computed tomography measurements of paraspinal muscle cross-sectional area and density in patients with chronic low back pain. Spine (Phila Pa 1976) 2003;28:1455-1460.

15. Ranson CA, Burnett AF, Kerslake R, Batt ME, O'Sullivan PB. An investigation into the use of MR imaging to determine the functional cross sectional area of lumbar paraspinal muscles. Eur Spine J 2006;15:764-773.
16. Campbell WW, Jensen ME, Motji E. Electrodiagnostic-radiographic correlation in subjects with suspected radiculopathy and fibrillations confined to paraspinal muscles. Muscle Nerve 1991;14:888889.

17. Haig AJ. Clinical experience with paraspinal mapping. II: A simplified technique that eliminates three-fourths of needle insertions. Arch Phys Med Rehabil 1997;78:1185-1190.

18. Macintosh JE, Bogduk N. 1987 Volvo award in basic science. The morphology of the lumbar erector spinae. Spine (Phila Pa 1976) 1987;12:658-668.

19. Elliott JM, Jull GA, Noteboom JT, Durbridge GL, Gibbon WW. Magnetic resonance imaging study of cross-sectional area of the cervical extensor musculature in an asymptomatic cohort. Clin Anat 2007;20:35-40.

20. Uden A, Johnsson KE, Jonsson K, Pettersson H. Myelography in the elderly and the diagnosis of spinal stenosis. Spine (Phila Pa 1976) 1985;10:171-174.

21. Herron LD, Mangelsdorf C. Lumbar spinal stenosis: Results of surgical treatment. J Spinal Disord 1991;4:26-33.

22. Leinonen $V$, Maatta $S$, Taimela $S$, et al. Paraspinal muscle denervation, paradoxically good lumbar endurance, and an abnormal flexion-extension cycle in lumbar spinal stenosis. Spine (Phila Pa 1976) 2003;28: 324-331

This CME activity is designated for 1.0 AMA PRA Category 1 Credit ${ }^{\mathrm{TM}}$ and can be completed online at me.aapmr.org. Log on to www.me.aapmr.org, go to Lifelong Learning (CME) and select Journal-based CME from the drop down menu. This activity is FREE to AAPMER members and $\$ 25$ for non-members.

\section{CME Question}

Among the study's conclusions, the authors determined that greater paraspinal muscle atrophy was associated with:

a. low back pain

b. greater denervation

c. advanced age

d. symptomatic spinal stenosis

Answer online at me.aapmr.org 